\title{
Characterization of liquefied products from model woody components in the presence of mineral acid catalysts
}

\author{
Q. Wang ${ }^{1}$, Q. Chen ${ }^{1}$, P. Apaer ${ }^{1}$, Q. Qian ${ }^{1}$, T. Maezono ${ }^{1}$, \\ N. Mitsumura ${ }^{1}$, H. Kurokawa ${ }^{1} \&$ X. Guo ${ }^{2}$ \\ ${ }^{I}$ Department of Environmental Science and Technology, \\ Graduate School of Science and Engineering, Saitama University, Japan \\ ${ }^{2}$ School of Environmental and Chemical Engineering, \\ Shanghai University, China
}

\begin{abstract}
Cellulose and lignin are the main structural polymers in the plant cell wall. Cellulose is the structural component of the primary cell wall of green plants, many forms of algae and the oomycetes. About $40-50 \%$ of woody matter is cellulose. Lignin is a highly cross-linked polymer created by the polymerization of substituted phenolic compounds, known as monolignols, such as coniferyl, pcoumaryl, and synapyl alcohol. Liquefaction process is one of the promising techniques for effective utilization of woody biomass for the lignocelluloses can be converted to liquid reactive materials as the bio-based materials. Cellulose would have an advantage of providing liquefied product with small range of variance. The phenolated woody components have high acidity in the presence of mineral acid catalysts and possess the constituents which can react with formaldehyde. In addition, lignin, one of the major woody components including the hydroxyl-benzyl structure, has the potential to react with formaldehyde. However, as its complexity in structure, the liquefaction mechanism and the liquefied products with phenol should be found out to solve some problems such as the reaction efficiency and low molecular weight products, and it will be useful to preparation of bio-based materials thought the liquefaction processes. In our study, two model woody components have been used under the different liquefaction conditions with phenol. In our experiments, the model cellulose component is specially used in the experiment to test the characteristics of the
\end{abstract}


products under different ratios. As the results, we found that the final liquefied products from model component substance of lignin only $17.2 \%(\mathrm{wt})$ and the growth rate is very low with the molecular weight (Mw) up to 2119 under the reaction temperature of $150^{\circ} \mathrm{C}$ and 3 hours in the liquefaction experiments. However, the model cellulose component was confirmed to contribute more. On the contrary, the $\mathrm{Mw}$ of raw woody powder material can be reach to 1851 . In a series of the mixing experiments, we found that the variation of $\mathrm{Mw}$ in the different experimental conditions determined by a gel permeation chromatography. From the results of liquefaction residue, we calculated the activation energy, and compared the value of those in different conditions. The solubility of the phenolated woody powder had been evaluated in eight organic solvents to evaluate the hydrogen bonding strengths of these solvents. It is very helpful for sustainable chemistry if polymeric materials can be effectively produced from the biomass liquefaction processes.

Keywords: woody components, liquefaction, gel permeation chromatography, eco-polymeric materials, mineral acid catalysts.

\section{Introduction}

As one of the methods of using the biomass effectively, composition of the resin which used the biomass as materials was mentioned. It is necessary to liquefy the biomass and the technique of this liquefaction as a proceeding to produce the compounds of resin. At the early studies of liquefaction, in addition to organic solvents, such as phenol and alcohol, woody biomass was put into the airtight container, and it began from having succeeded in obtaining a viscous liquid by putting $250^{\circ} \mathrm{C}$ heat and pressure. Then, it succeeded in making pressure into normal pressure by adding an acid catalyst, and lowering reaction temperature to $150^{\circ} \mathrm{C}[1]$.

Lin used GG (guaiacylglycerol- $\beta$-guaiacyl), as a lignin model compound, carried out the relevant researches about liquefaction reaction mechanism of lignin compounds in the presence of sulfuric acidic catalyst $[2,3]$ and without catalysts $[4,5]$. They had also attempted to clarify the reaction mechanism of cellulose with phenol under the acid-catalyzed conditions. It was found that the yield ratios of various compounds in the end reaction products are greatly dependent on the reaction conditions. Therefore, by controlling these reaction conditions, it is possible to adjust the structure and properties of the end liquefaction products [6]. Kobayashi et al. [7] reported that the wood contents of liquefied woody were limited to low levels, because the condensation reaction occurred concurrently among the wood components themselves during liquefaction. Recently, cellobiose, cellulose, and starch were used as model compounds, and their liquefaction mechanisms in the presence of polyhydric alcohol or phenol, with or without sulfuric acid as catalyst, were studied [8-10]. Sung et al. [11] reported the phenol liquefaction at the higher temperature of $150^{\circ} \mathrm{C}$ is considered to be via a predominant reaction pathway, mainly accompanying with the condensation reaction of the phenolic compounds produced during phenol liquefaction of cellulose. 
In our study, model woody substances such as cellulose powder, alkaline lignin and their mixture were used for liquefaction processes to analyze the reaction mechanism of woody substances using phenol as an organic reactant. Woody powder was also liquefied as the comparison. Liquefaction efficiency and molecular weight distribution were evaluated from the liquefaction products.

\section{Materials and methods}

\subsection{Materials}

In our study, Japanese cedar (Cryptomeria Japonica), as the woody material, had been collected from the company of waste treatment factory. Cellulose (CAS No: 9004-34-6 MP Blomedicais, LLC) and lignin (Alkaline, CAS No: 9005-53-2 TCI. Co, Ltd) was bought on the market as model woody materials. The information of these model substances is listed in table 1 .

Table 1: Characteristics of cellulose and lignin as model woody materials.

\begin{tabular}{ccc}
\hline Item & Cellulose microcrystalline & Lignin (Alkaline $)^{\mathrm{a}}$ \\
Formula & $\left(\mathrm{C}_{6} \mathrm{H}_{10} \mathrm{O}_{5}\right) \mathrm{n}$ & $\mathrm{C}_{10} \mathrm{H}_{12} \mathrm{O}_{3}$ \\
Weight & $(162.06) \mathrm{n}$ & $210.2 \mathrm{~g} / \mathrm{mole}$ \\
Structure & $150.2 \mathrm{~g} / \mathrm{mole}_{11} \mathrm{H}_{14} \mathrm{O}_{4}$ \\
\hline
\end{tabular}

${ }^{a}$ The product is composed of three primary precursors coniferyl alcohol, mustard alcohol, p-coumaric alcohol dehydrogenase enzyme aggregates formed by plant polymers.

The oven-dried woody powder had been milled in smashing equipment and retained at the size ranges of 10-100 mesh screens were used for the test. All of these samples of woody materials were dehydrated in an oven at $105^{\circ} \mathrm{C}$ for 12 hours. The main different acidic catalysts such as $\mathrm{H}_{2} \mathrm{SO}_{4}(95 \%), \mathrm{H}_{3} \mathrm{PO}_{4}(85 \%)$, phenol and other reagents were prepared with analytical grade reagents in accordance with the Japanese Industrial Standard (JIS) bought from Wako Pure Chemicals, Co. Ltd., Japan.

\subsection{Chemical composition of liquefied woody materials}

In the proximate and ultimate analysis, the ash content of the residue left after the combustion of woody sample is performed according to the industrial 
standard method (JIS-M8812). $7.7 \mathrm{wt} \%$ of the moisture of woody sample is determined by measuring the weight loss after drying the sample at $105^{\circ} \mathrm{C}$ in an oven. $79.1 \mathrm{wt} \%$ of volatile matter was tested by heating the woody powder to $900^{\circ} \mathrm{C}$ under carefully controlled conditions and measuring the weight loss. Then, $12.6 \mathrm{wt} \%$ of fixed-carbon in woody materials was calculated by subtracting the percentages of moisture, volatile matter, and ash of the woody samples. Other components were also quantitatively analyzed for the waste woody powder used in our experiments which were summarized in table 2 .

Table 2: Composition analysis ( $\mathrm{wt} \%)$ of waste woody material.

\begin{tabular}{lcc}
\hline & Composition analysis & Liquefied woody materials \\
\hline \multirow{4}{*}{ Carbohydrate } & Holocellulose & 72 \\
& Cross and Bevan cellulose & 61 \\
& Alpha Cellulose & 52 \\
& Klason Lignin & 23 \\
\hline \multirow{2}{*}{ Solubility } & $1 \% \mathrm{NaOH}$ & 26.2 \\
& EtOH/Benzene & 3.3 \\
\hline
\end{tabular}

\subsection{Liquefaction experiments}

Liquefaction experiments of waste woody materials and model substances were carried out by varying the weight charge ratio of wood to phenol with $1 / 4$ and the reaction temperature at $110^{\circ} \mathrm{C}, 140^{\circ} \mathrm{C}$ and $170^{\circ} \mathrm{C}$ controlled by an oil bath. The raw materials put into a $500 \mathrm{ml}$ three necked flask equipped with stirrer. Reactants treated with methanol as the diluents. We added the catalyst to the reactant as the reaction start time, and added the methanol into liquefied products as the stop of reaction time.

\subsection{Analysis of characteristics of liquefied products}

\subsubsection{Comparison experimental of different acidic catalysts}

Experimental liquefaction of waste woody materials were carried out by varying the weight charge ratio of wood to phenol with $1 / 4$ and the reaction temperature at $150^{\circ} \mathrm{C}$ by oil bath. Into a $500 \mathrm{ml}$ three necked flask equipped with stirrer. In addition, the same weight ratio of wood/phenol/ acid catalyst were using in the comparison experimental. Otherwise, the characteristics of produce research experimental was liquefied for 3 hours with two kinds of acidic catalysts, we tested the residues, viscosity, nonvolatility to evaluate the correlation.

\subsubsection{Viscosity measurement of liquefied waste woody materials}

The viscosity of liquefied woody materials was measured with a viscometer (Model VT-04F, RION Co. Ltd., Japan) in $300 \mathrm{ml}$ standard beaker at $25 \pm 3^{\circ} \mathrm{C}$. The viscosity is measured using a viscosity measurement stick to obtain direct readings in decipascal-seconds (dPa.s). 


\subsubsection{Measurement of liquefaction residue}

The liquefied woody and model substances material were weighted and diluted with methanol, and Whatman filter papers was used to collect the liquefied residue. Here, Solvent-insoluble residue in equation (1) means that the weight of liquefied residue through filtration which diluted by methanol from liquefied products, and raw material means that the weight of the reactants The liquefied residue was dried in a heating oven at $105^{\circ} \mathrm{C}$ during 12 hours and calculated the residues by equation (1).

Liquefied rate $(w t \%)=($ Solvent-insoluble residue $/$ Raw material $) \times 100 \%$

\subsubsection{Measurement of nonvolatility of resultant}

About (1.5-3.0) $\pm 0.5 \mathrm{~g}$ of liquefied products were weighted and dried using a oven at $180 \pm 1^{\circ} \mathrm{C}$ by 1 hour according to JIS-K6910 to remove the un-reacted phenol. The nonvolatility can be calculated by residue after oven-dry according the following equation (2).

Nonvolatility $(w t \%)=($ Residue after oven-dry $/$ liquefied products $) \times 100 \%$

\subsubsection{Measurement of liquefied products}

In this study, we also used the Liquefied products to evaluate the liquefaction reaction efficiency and reaction rate. The method of calculation is to subtract the weight of liquefied residence from nonvolatility by the following equation (3)

$$
\text { Liquefied products }(w t \%)=(\text { Nonvolatility })-(\text { Solvent-insoluble residue })
$$

\subsection{Molecular weight distribution of liquefied products measured by gel permeation chromatography}

The solvent was removed by using a rotary evaporator. The sample was then diluted with $0.1 \mathrm{wt} \%$ of sample in $99.8 \%$ tetrahydrofuran (THF) and filtered through a $0.45 \mu m$ PVDF filter. The filtrate was analyzed through high performance liquid chromatography (HPLC) using a GPC (HPLC Pump JASCO PU-2080) equipped with RI Detector JASCO RI-2031 and a Shodex GPC KF806 column which exclusion limit molecular weight $\left(2 \times 10^{7}\right)$. Measurements were conducted at $40^{\circ} \mathrm{C}, 280 \mathrm{~nm}$, and a flow rate of $1 \mathrm{~mL} / \mathrm{min}$ using $99.8 \%$ THF as a mobile phase. The average molecular weight of the samples was calculated by using a calibration curve of monodisperse polystyrene standards. The peak on the GPC curve corresponding to the phenol that was used for the liquefaction was excluded in the calculation of the average molecular weight. As the results, the differential molecular weight distribution (D.MWD) can be used to explain and compare with the analytical results from gel permeation chromatography clearly. 


\section{Results and discussions}

\subsection{Characteristics and behavior of liquefied woody material}

Kobayashi et al. have done the liquefaction of cellulose powder, steamed lignin, alkali lignin, and their mixture was carried out to estimate the liquefaction process of wood in the system using polyethylene glycol as a coexisting medium [12]. They found that Analysis of the mixture showed that its behavior resembled that of wood in changes of molecular weight distribution and the main functional groups. In our study, we analysis the $\mathrm{Mw}$ of raw woody powder material can be reach to 1851 , and it near to the result of mixture. The model substances of cellulose and lignin, the similar weight distribution was given in results.

\subsection{Effect of reaction temperature on liquefaction of model substances}

We used model substances mixed by a 5:3 mixtures of cellulose to lignin as simulated coniferous tree and a 6:2 mixture of those as simulated broadleaf tree (figure 1), basing on the composition ratios of the proportion of coniferous and broadleaf trees which according to reference data Nippon Paper Group.
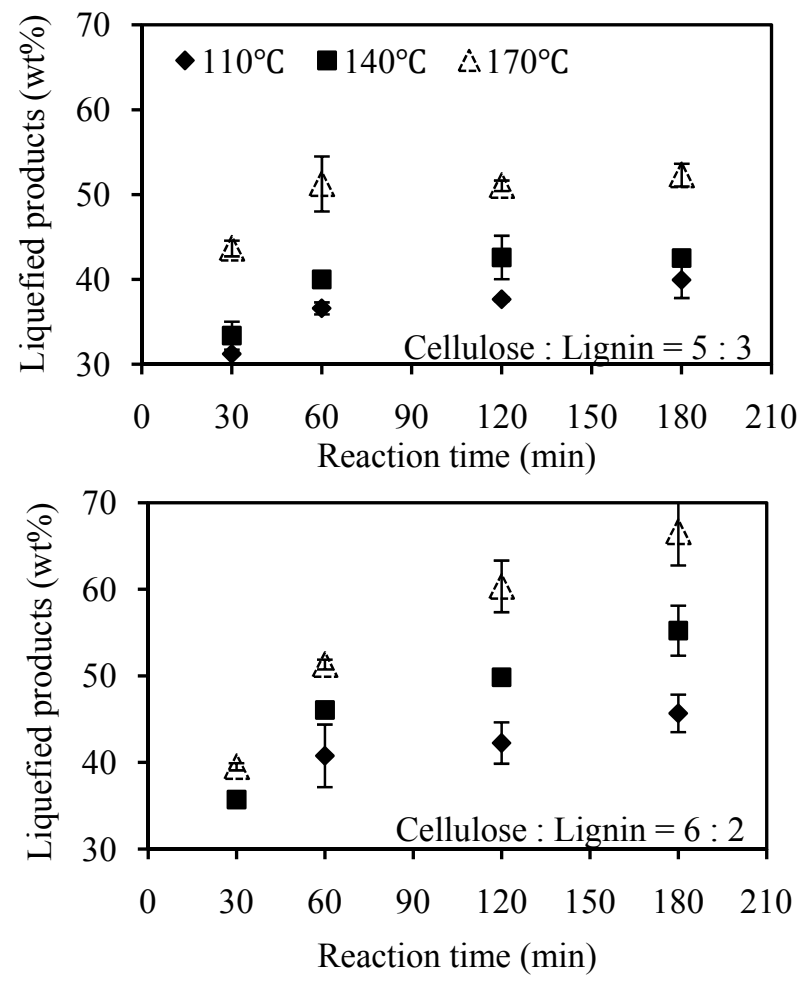

Figure 1: $\quad$ The liquefied products by two kinds of mixture at 3 hour. 
According to the results of figure 1, the liquefied products have increased at the two ratios amount of mixture with the rise of reaction temperature. Especially, after the temperature rose to $170^{\circ} \mathrm{C}$, the more products pronounced increased at 3 hours. Comparison of two graphs, it can be found that contains a high percentage of the amount of cellulose can get more resultant. In other words, liquefied residual is declining with the reaction temperature. At the first hour, the reaction speed is faster than other time, and it presents a more intense reaction phenomenon.

Zhang et al. [8] reported that the temperature of $120^{\circ} \mathrm{C}$ provides the lowest molecular weight. This temperature, however, does not provide satisfactory liquefaction. As temperature rises, the liquefaction proceeds rapidly and the time reaches to the maximum liquefaction is shortened. At the lower temperature, and the content of cellulose is low, we can get the different molecular weight distribution and lower average molecular weight (figure 2). According to figure 3 and figure 4, the result of molecular weight distribution in present of sulfuric acid catalyst and rate of cellulose and lignin is 5:3 under 3 different temperatures. As the temperature rose, the liquefied products gain of the new condensed residue. These may come from liquefied products of self-condensed polymerization. At the beginning of liquefaction, cellulose degraded to the levulinic acid derivatives, the aromatic derivatives react with them. As a result, the residue was produced. It can be seen from the results, varies with the temperature increased, the product volume also increased. And the products of high molecular weight also increased. Increment of the reaction temperature can promote the condensation of products. These findings clearly indicate that the newly formed residue is originated from the products of cellulose and contains the bound phenol. In other words, phenol plays as a role of self-condensed reagent in the residue, resulting in its weight gain in liquefied products.

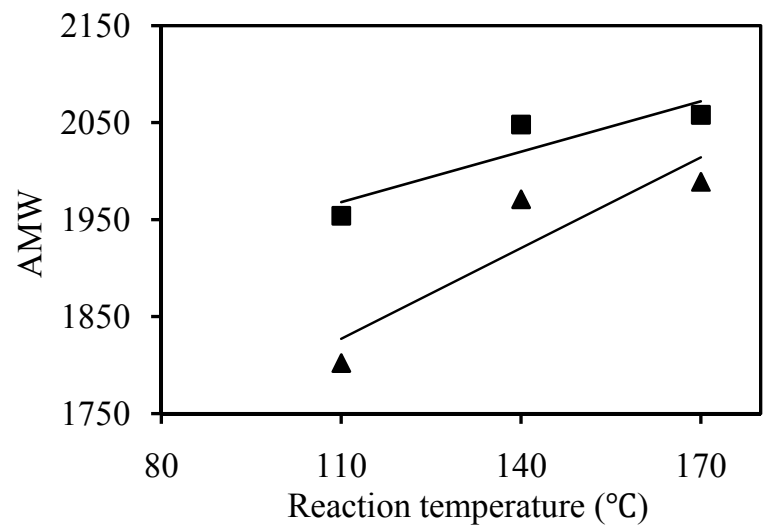

Figure 2: Relationship between average molecular weight (AMW) and reaction temperature. ( $\Delta$ Cellulose: Lignin $=5: 3$; Cellulose: Lignin $=6: 2$ ). 


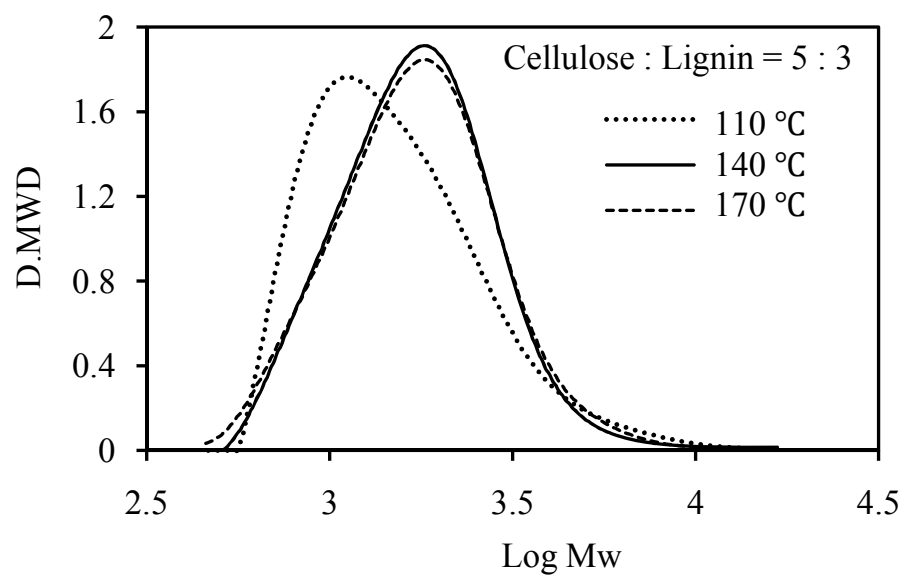

Figure 3: Differential molecular weight distribution (D.MWD) of liquefied products in present of sulfuric acid catalyst with the mixture of cellulose to lignin is 5:3 (simulated coniferous tree) under 110, 140 and $170{ }^{\circ} \mathrm{C}$.

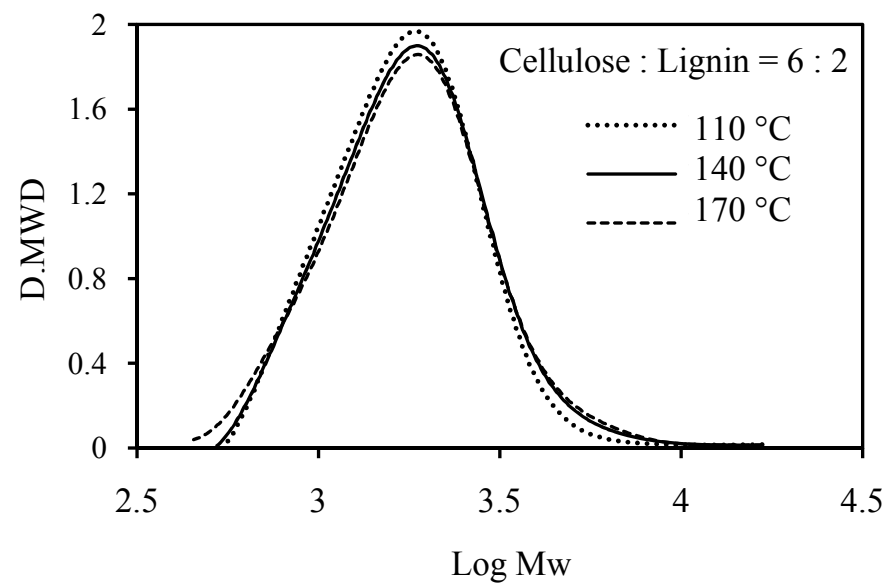

Figure 4: D.MWD in present of sulfuric acid catalyst with the mixture of cellulose to lignin is 6:2 (simulated broadleaf tree).

\subsection{Effect of the catalyst on woody liquefaction}

In figure 5 and table 3, the result of liquefied products and average molecular weight has been shown. $8 \% \mathrm{wt}$ and $20 \%$ wt of the catalyst amounts were added to different cases respectively. The larger amount of catalyst was added in the two reactions which will lead to react, more liquefied products were produced. However, the molecular weight distribution results showed no change until nearly three hours. It can be considered that the reaction efficiency will be 
Table 3: The result of average molecular weight which under the different (8wt $\%$ and $20 w t \%$ of phenol) amount of sulfuric acid catalyst.

\begin{tabular}{clccc}
\hline & \multicolumn{2}{c}{ Cellulose $:$ Lignin $=5: 3$} & \multicolumn{2}{c}{ Cellulose :Lignin=6:2 } \\
& $8 \mathrm{wt} \%$ & $20 \mathrm{wt} \%$ & $8 \mathrm{wt} \%$ & $20 \mathrm{wt} \%$ \\
\hline $\mathrm{Mn}$ & 1545 & 1503 & 1597 & 1453 \\
$\mathrm{Mw}$ & 1971 & 1942 & 2048 & 2150 \\
$\mathrm{Mz}$ & 2726 & 2688 & 2817 & 3211 \\
$\mathrm{Mw} / \mathrm{Mn}$ & 1.28 & 1.29 & 1.28 & 1.48 \\
\hline
\end{tabular}

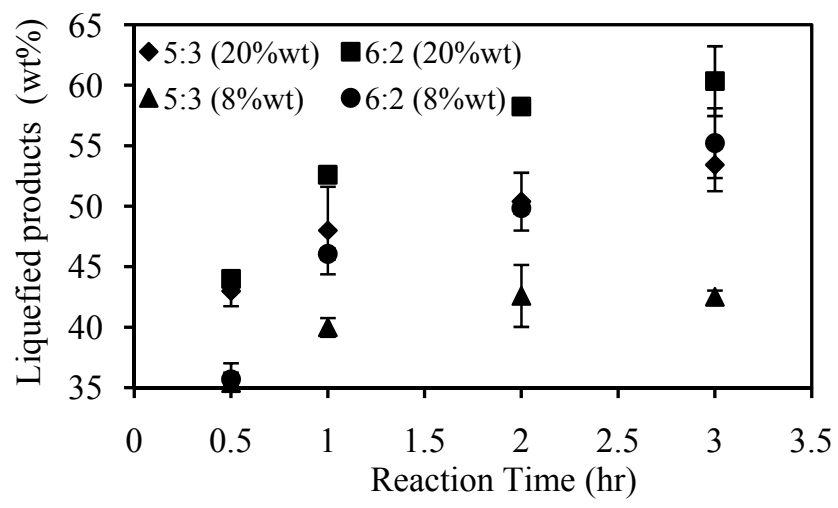

Figure 5: Liquefied products changed under different amounts of catalyst.

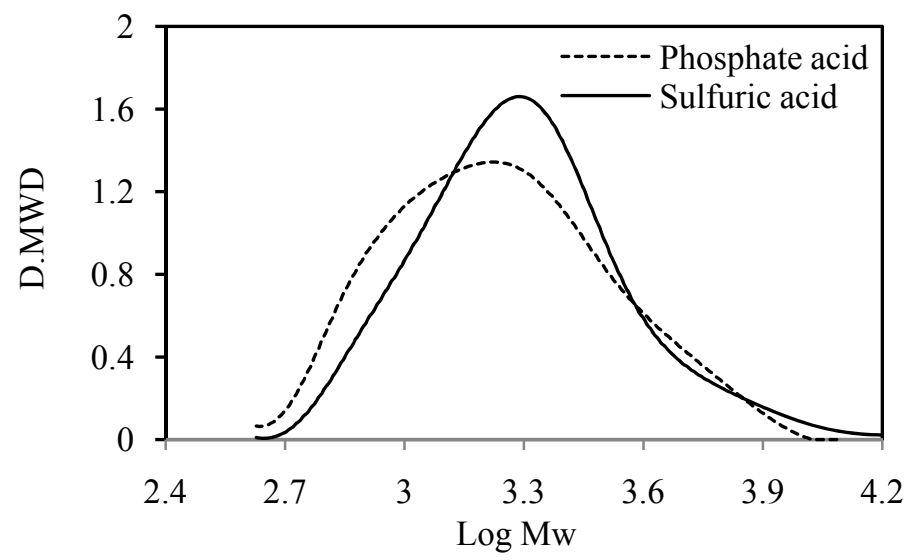

Figure 6: Differential molecular weight distribution of liquefied products in present of sulfuric acid catalyst and phosphate acid catalyst.

increased with the increased of the usage amount of catalyst. Furthermore, the upward tendency of the condensation reaction was not able to be seen. The result of figure 6 having used the different catalyst is compared and in the case of 
phosphoric acid, molecular weight distribution is wider. The results confirmed that the product affects the chemical structure by different acid catalysts.

\subsection{Effect of the reaction time on woody liquefaction}

Figure 7 shows the differential molecular weight distribution with reaction time at 30,60 and $120 \mathrm{~min}$ in present of sulfuric acid catalyst. The solid line is the
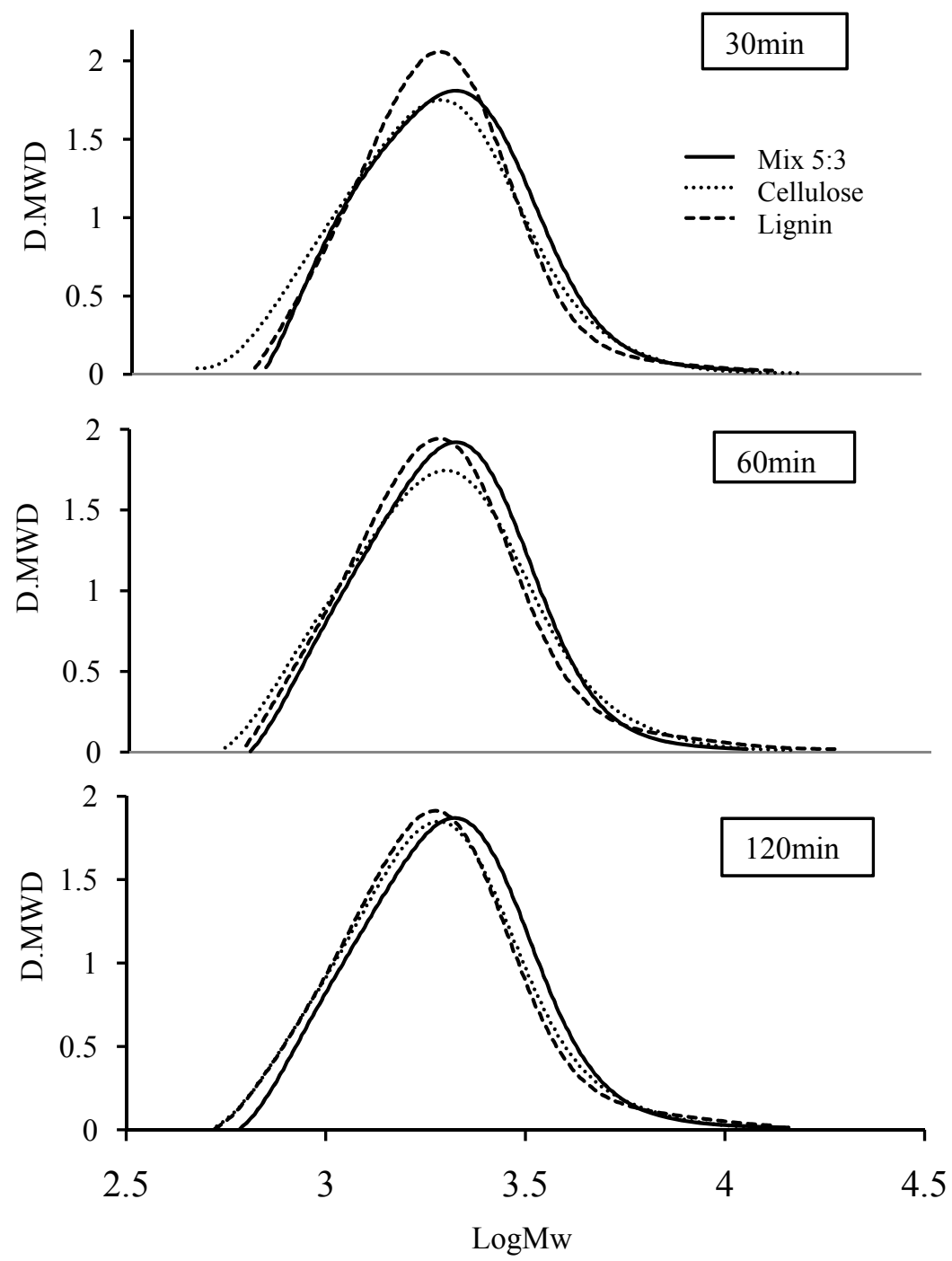

Figure 7: Differential molecular weight distribution of liquefied products in present of sulfuric acid catalyst during 30,60 and $120 \mathrm{~min}$. 
result of mixed case In order to investigate whether it is what a condensation reaction depends on coexistence of the sugar ingredient of cellulose origin, and polyphenol of lignin origin, or it is the characteristic to depend on using woody samples, the last series comparative experiments were conducted.

From the results can be seen on the figure 7 , we found that mixed cases, molecular weight distribution curve slightly skewed to the right, and it was reported that the molecular weights of the liquefied products of cellulose were distributed over a wide range of molecular weight, and the derivatives of levulinic acids remained after a long reaction time without condensing. Meanwhile no major functional groups of steamed lignin repolymerized during the liquefaction [12]. In mixed cases, generate new material to improve the molecular weight. By the interaction of the cellulose which carried out solution polymerization, and the aromatic derivative of lignin origin, we thought that a condensation reaction occurred. The upward tendency of the condensation reaction was checked. It is clearly shown that the condensation reaction took place by the mutual interaction between cellulose and lignin. The higher content of cellulose was shown that strengthen condensation reaction. It was considered that detailed mechanism of the condensation reaction should be researched by the development of waste woody polymeric materials [13] for sustainable chemistry.

\section{Conclusion}

In this study, we examined the relevance of liquefaction conditions, the molecular weight, or molecular weight distribution by using a GPC. It was investigated whether it is what a condensation reaction depends on coexistence of the sugar ingredient of cellulose origin, and polyphenol of lignin origin, or it was a characteristic to depend on using woody samples. When reaction efficiency was raised, the relevance of the output characteristic was analyzed. Within 3 hours of the reaction, it is shown that the temperature will influence on output performance as a change factor of reaction conditions. The relevance of the upward tendency of the amount of catalyst addition and a condensation reaction was not confirmed. The influences of acid catalyst on the structure of liquefied products have been confirmed. When the mixture of cellulose and lignin was liquefied, the condensation reaction occurred, but when the condensation reaction occurred from a part of insoluble residue having been formed by the interaction of the cellulose which carried out solution polymerization, and the aromatic derivative of lignin origin. The upward tendency of the condensation reaction was checked. It is clearly shown that the condensation reaction took place by the mutual interaction between cellulose and lignin. The higher content of cellulose was considered that strengthen condensation reaction. In our future work of woody polymeric materials for sustainable chemistry, we will try to separate the substances from condensation reaction and un-reacted materials. 


\section{Acknowledgement}

Some works of this study were supported by the special funds for Basic Researches (B) (No. 22404022, FY2010 2012) of Grant-in-Aid for Scientific Research of the Japanese Ministry of Education, Culture, Sports, Science and Technology (MEXT), Japan.

\section{References}

[1] T. Asano et al., The effect of the ozonization exerted on liquefaction of the research-wood about resinification and recycling of woody system waste, 2007, Japanese.

[2] L.Z. Lin et al., Liquefaction mechanism of [beta]-O-4 lignin model compound in the presence of phenol under acid catalysis. Part 1. Identification of the reaction products, Holzforschung, 55, 617-624, $2001 \mathrm{a}$.

[3] L.Z. Lin et al., Liquefaction mechanism of [beta]-O-4 lignin model compound in the presence of phenol under acid catalysis. Part 2. reaction behaviour and pathway, Holzforschung, 55, 625-630, $2001 \mathrm{~b}$.

[4] L.Z. Lin et al., Liquefaction mechanism of lignin in the presence of phenol at elevated temperature without catalysts. I. structural characterization of the reaction products, Holzforschung, 51, 316-324, 1997a.

[5] L.Z. Lin et al., Liquefaction mechanism of lignin in the presence of phenol at elevated temperature without catalysts. II. Reaction pathway, Holzforschung, 51, 325-332, 1997 b.

[6] L.Z. Lin et al., Liquefaction mechanism of cellulose in the presence of phenol under acid catalysis, Carbohydrate Polymers, 57, 123-129, 2004.

[7] M. Kobayashi et al., Analysis on residue formation during wood liquefaction with polyhydric alcohol, J Wood Sci, 50:407-414, 2004.

[8] Y.C. Zhang et al., Characterization of liquefied product from cellulose with phenol in the presence of sulfuric acid, Bioresource Technology, 97, 313321, 2006.

[9] Sung P.M et al., 2006, Effect of orangic sulfonic acids as catalysts during phenol liquefaction pinus radiate bark, Ind Eng. Chem, 12, 720-726.

[10] T. Yamada et al., 2001, Characterization of the products resulting from ethylene glycol liquefaction of cellulose, $J$ Wood Sci, 47, (6), 458-464.

[11] Sung P.M et al., 2009, Liquefaction of cellulose in the presence of phenol using p-toluene sulfonic acid as a catalyst, Journal of Industrial and Engineering Chemistry, 15, 743-747.

[12] M. Kobayashi et al., 2004, Analysis on residue formation during wood liquefaction with polyhydric alcohol, The Japan Wood Research Society, 50, 407-414.

[13] Q. Wang et al., 2010, Liquefaction processes and characterization of liquefied products from waste woody materials in different acidic catalysts, The Sustainable World, WIT Transactions on Ecology and the Environment, 142, 343-354. 